Supporting information file

\title{
Compact Glow Discharge for the Elemental Analysis of Aqueous Samples.
}

Michael R. Webb, Francisco J. Andrade, and Gary M. Hieftje

Department of Chemistry, Indiana University, 800 East Kirkwood Avenue, Bloomington, IN 47405

Figure S-1. Background (aqueous blank adjusted to $\mathrm{pH} 1.0$ with HNO3) spectrum of the SCGD between 200 and $800 \mathrm{~nm}$. A long-pass filter was used in for wavelengths over $500 \mathrm{~nm}$ to block second-order light. Features include $\mathrm{OH}$ bands (bandheads at 260.9, 281.1 , and $306.4 \mathrm{~nm}$ ), the $\mathrm{N}_{2}$ second positive system (bandheads visible from 337.1 to $405.9 \mathrm{~nm})$, a series of $\mathrm{O}$ II lines (391.2 to $470.1 \mathrm{~nm})$, the $\mathrm{H}_{\beta}(486.1 \mathrm{~nm})$ line, $\mathrm{Na}$ I lines $(589.0 \& 589.6 \mathrm{~nm})$, the $\mathrm{H}_{\alpha}(656.3 \mathrm{~nm})$ line, K I lines $(766.5 \& 769.9 \mathrm{~nm})$, and $\mathrm{O} \mathrm{I}$ lines (777.2, 777.4, \& $777.5 \mathrm{~nm})$.

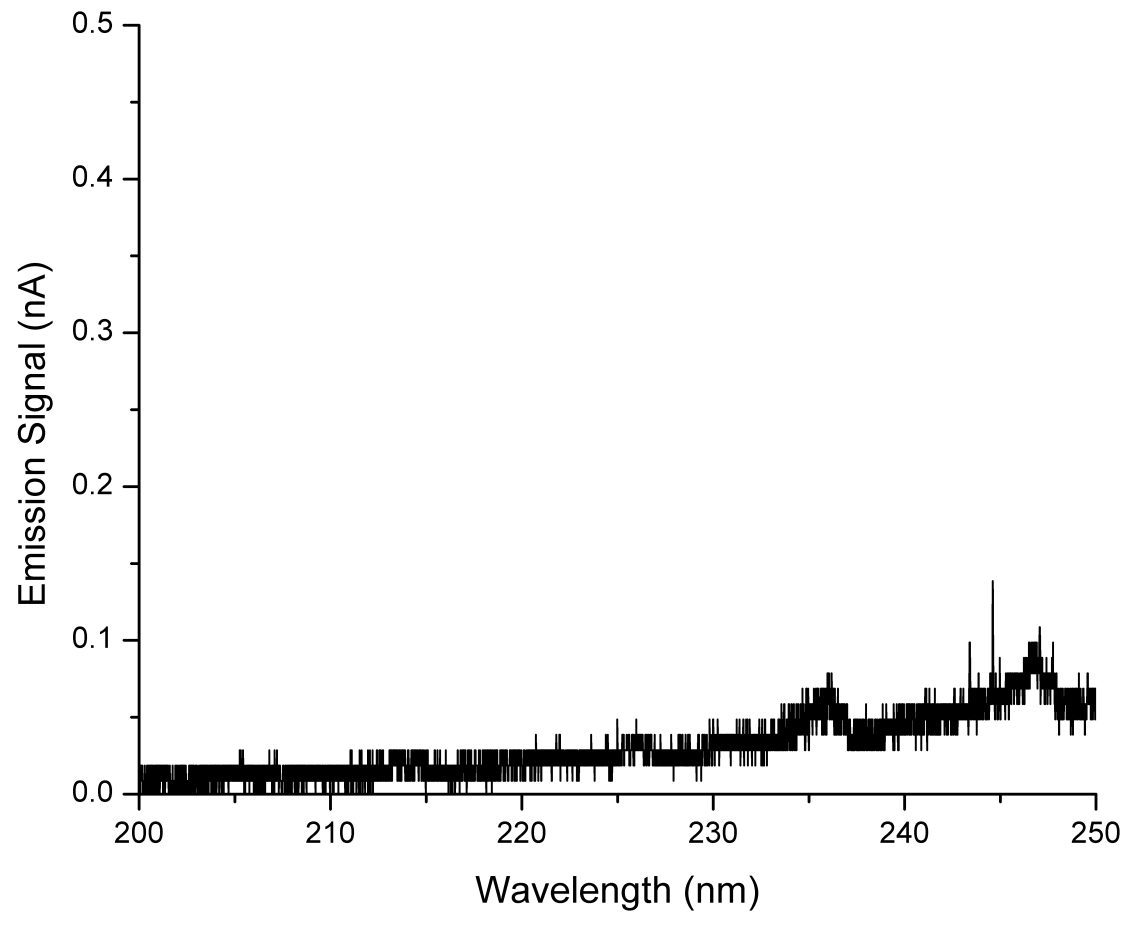

(a) 


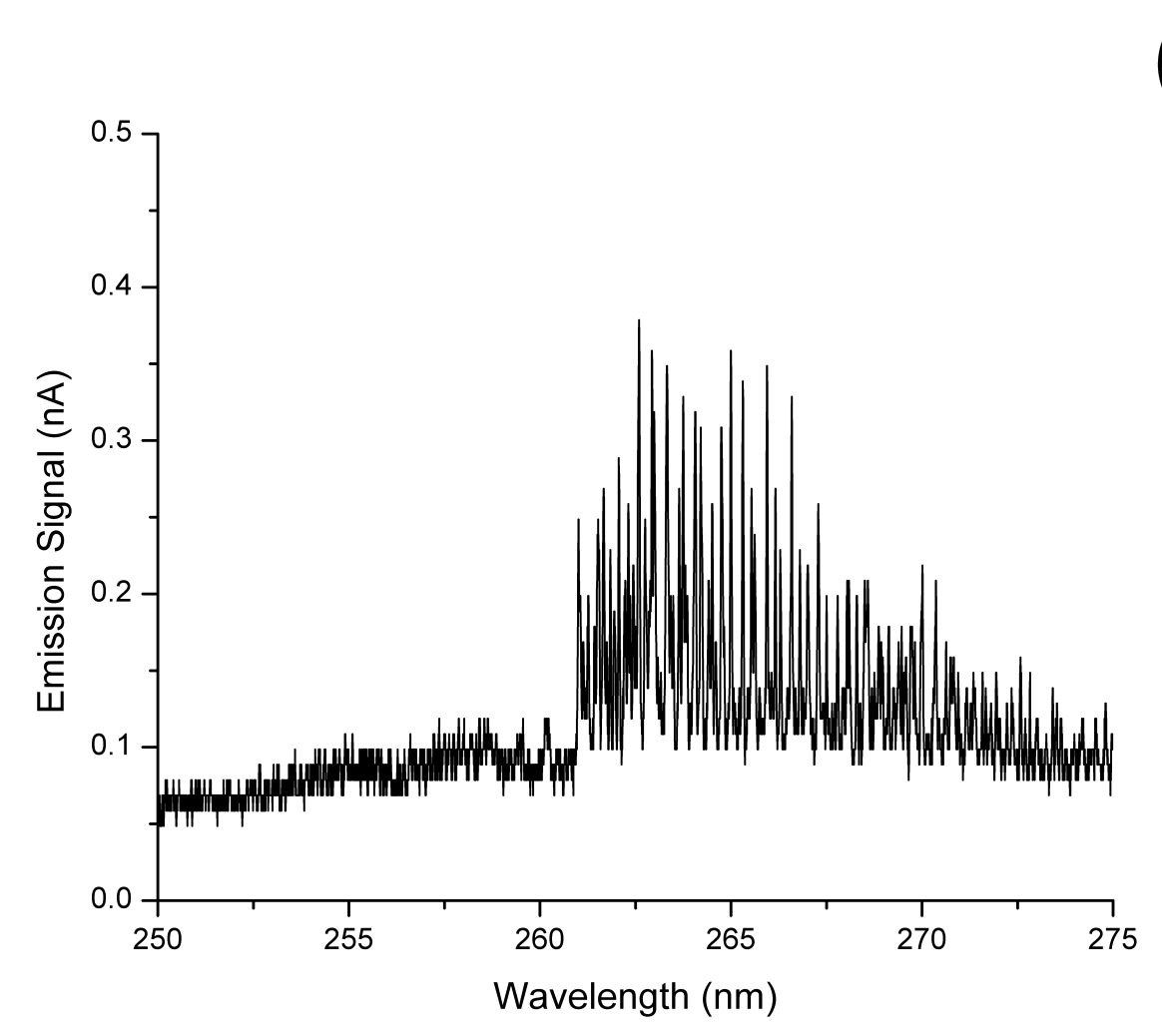

(b)

(c)

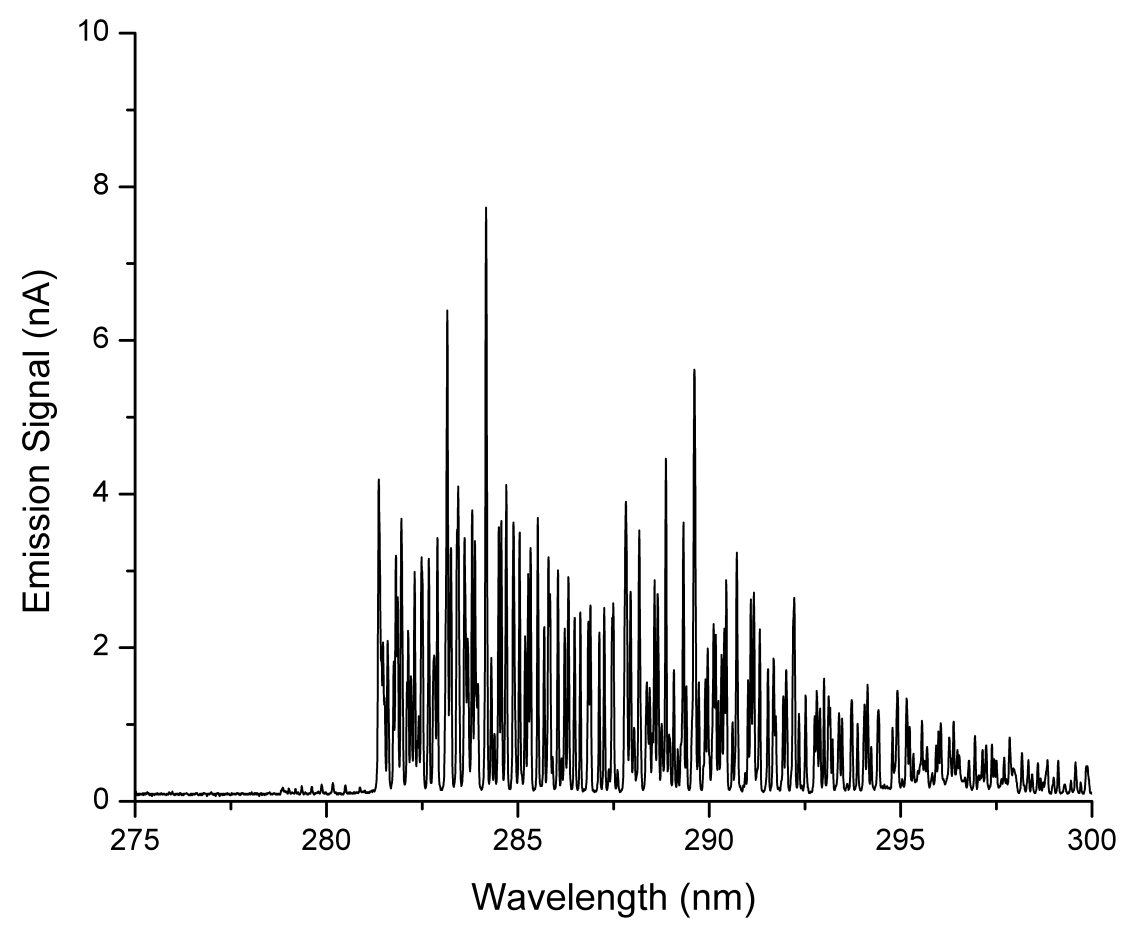


(d)

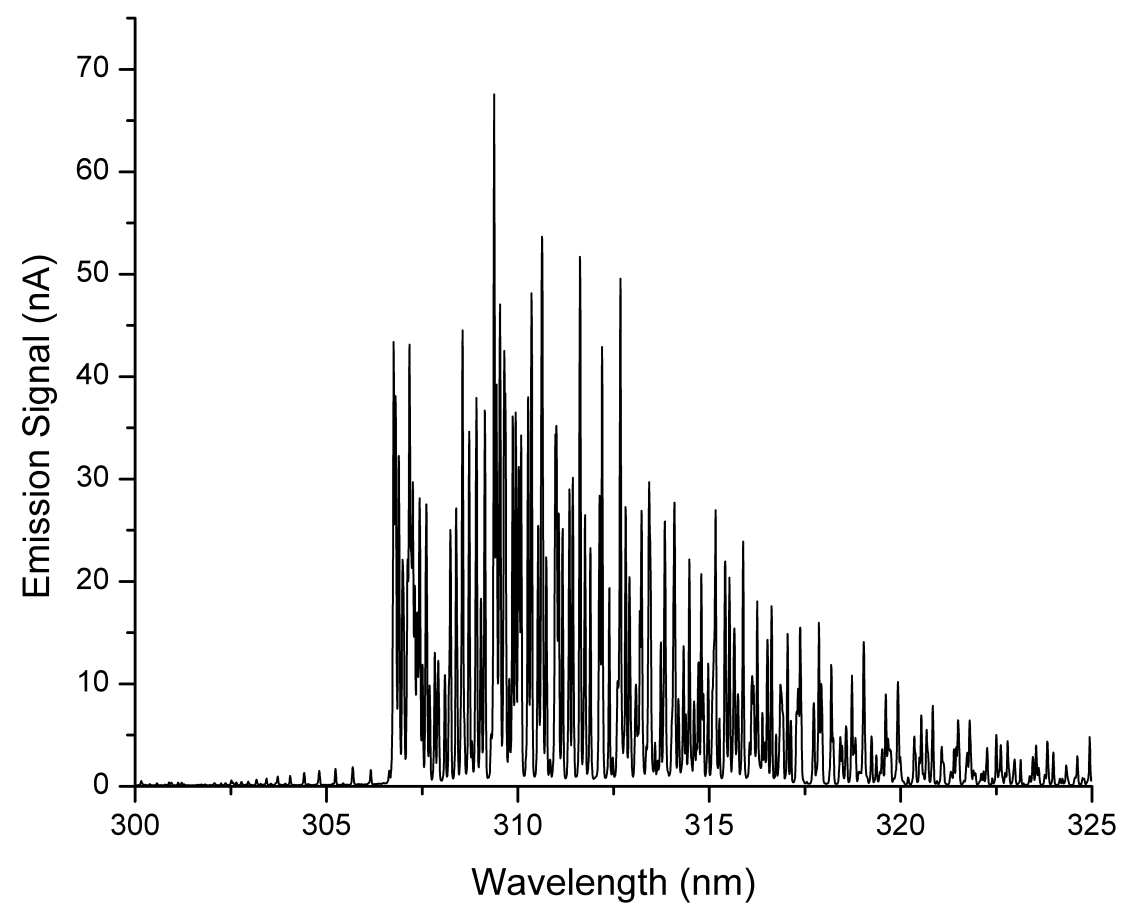

(e)

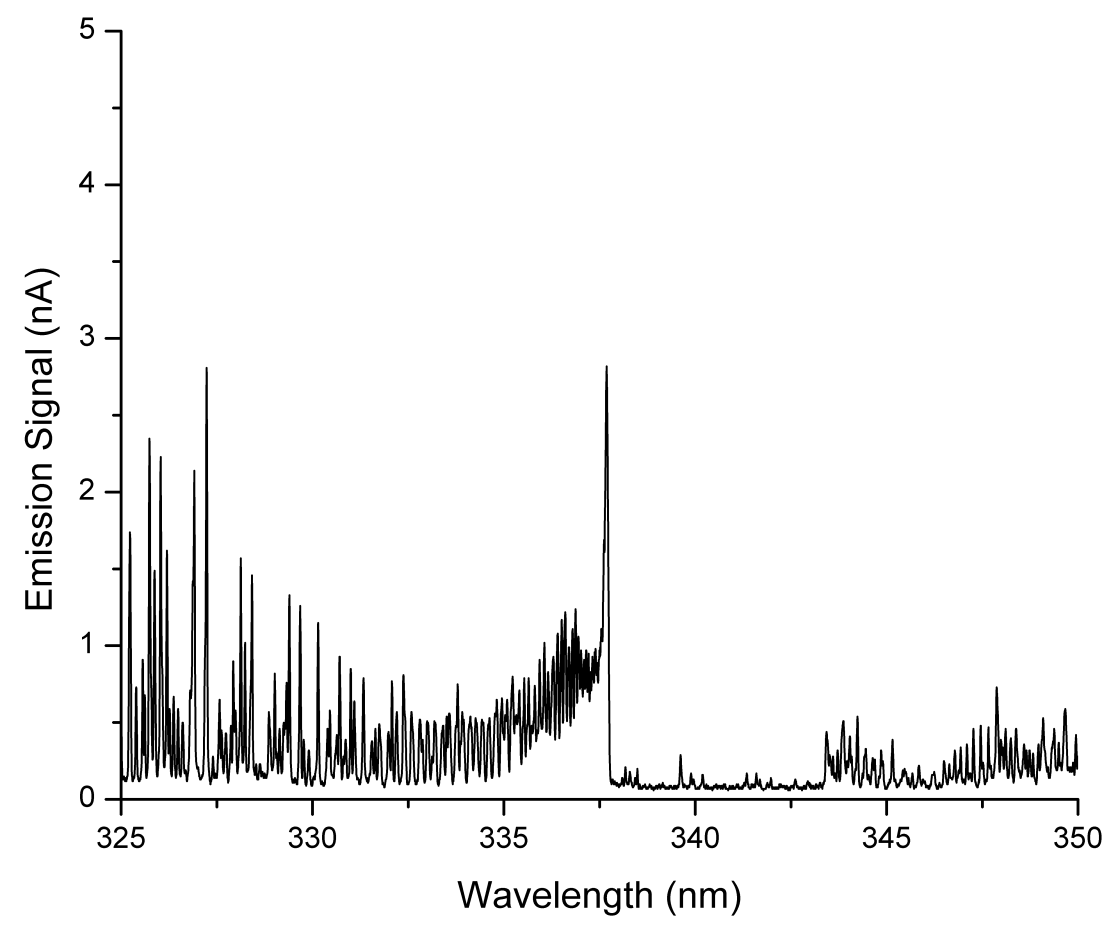


(f)

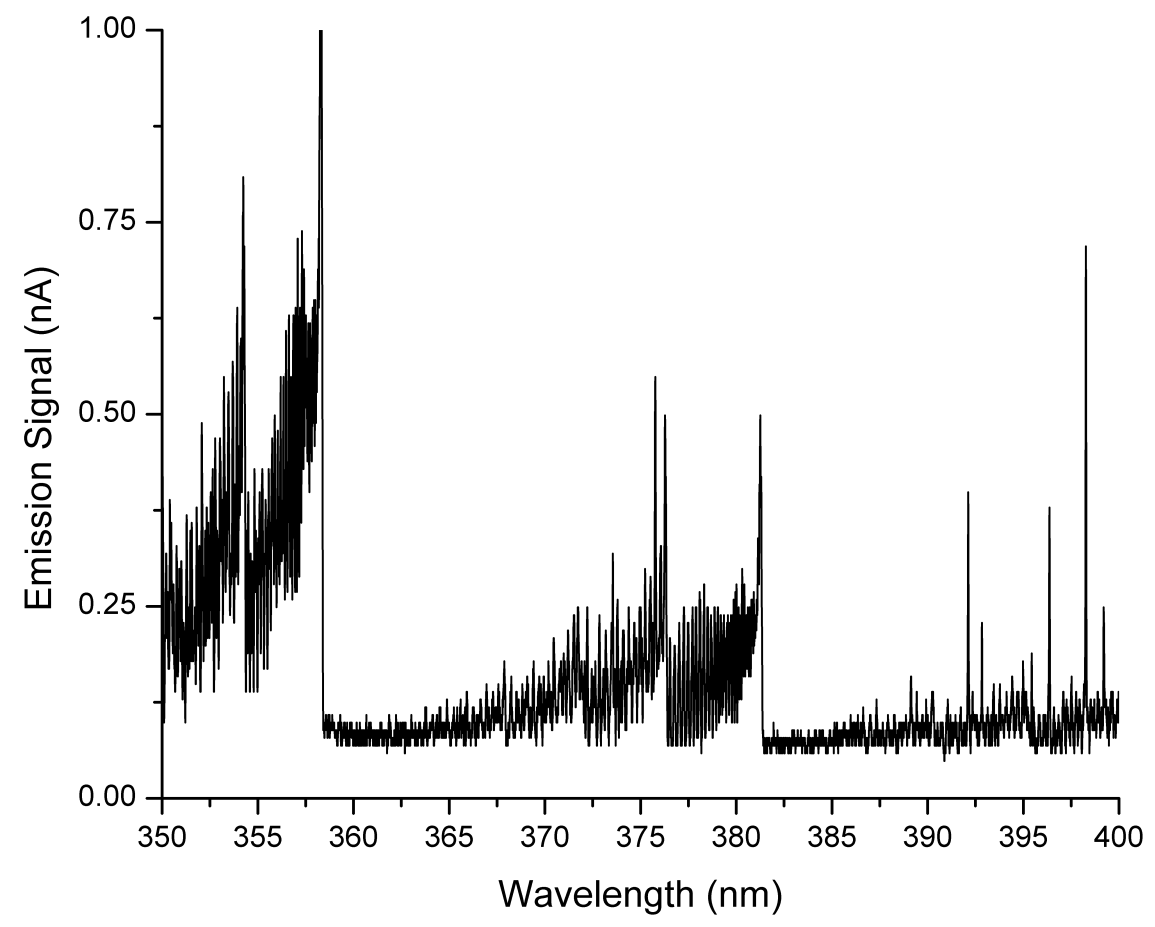

(g)

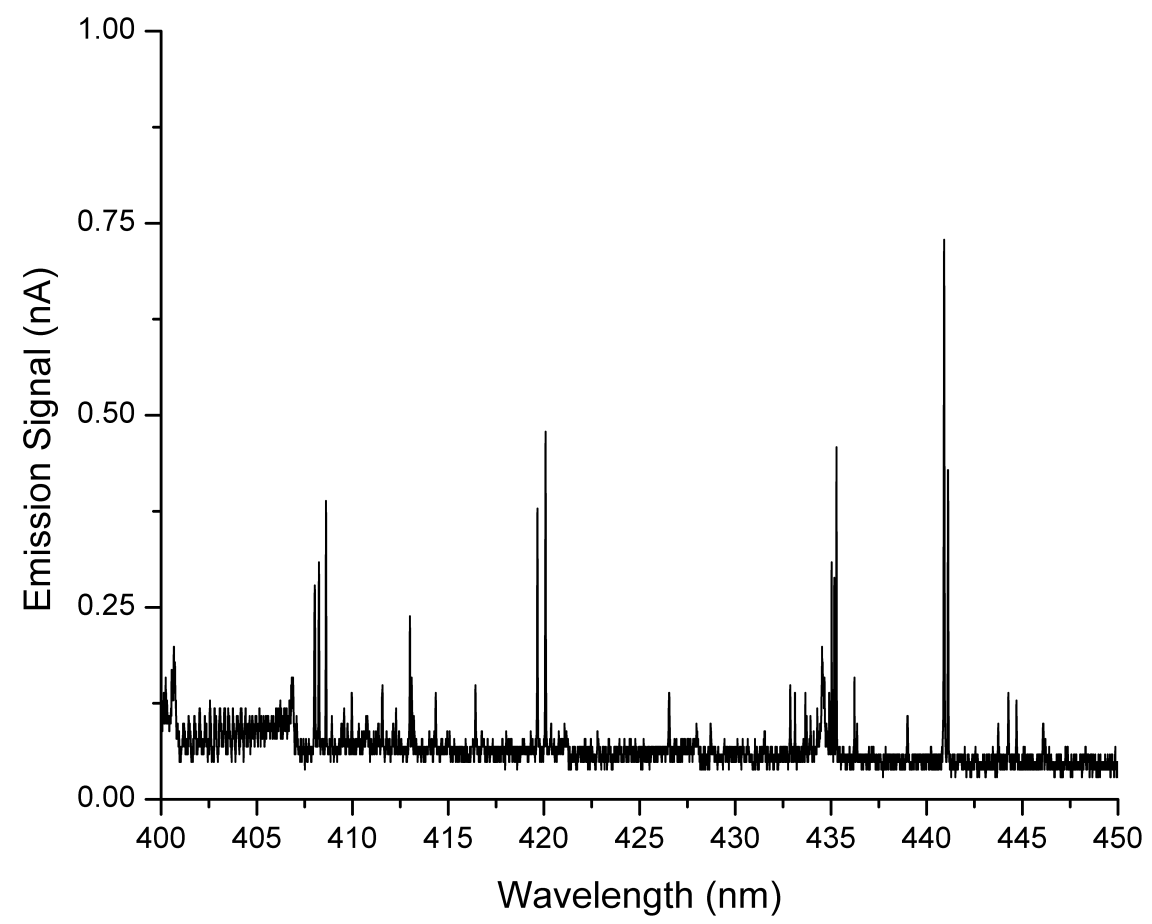


(h)

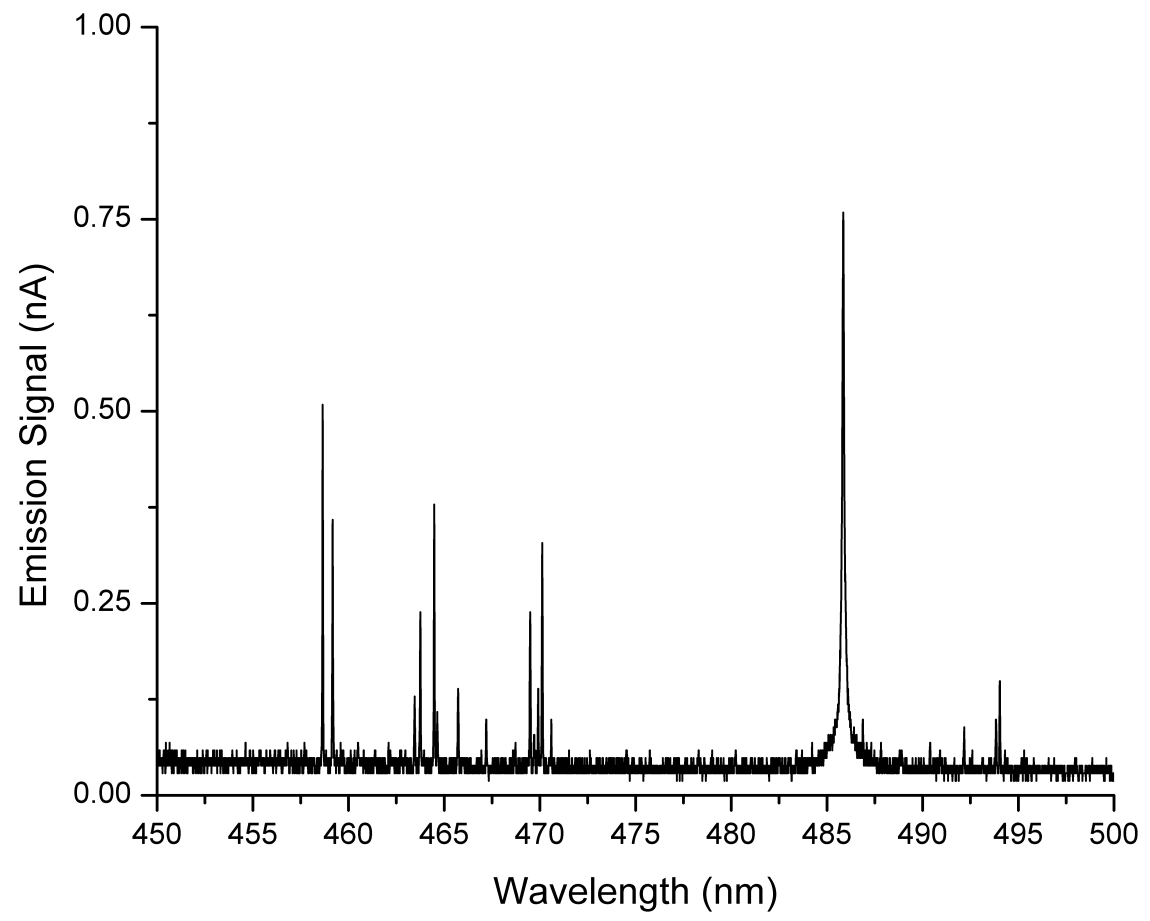

(i)

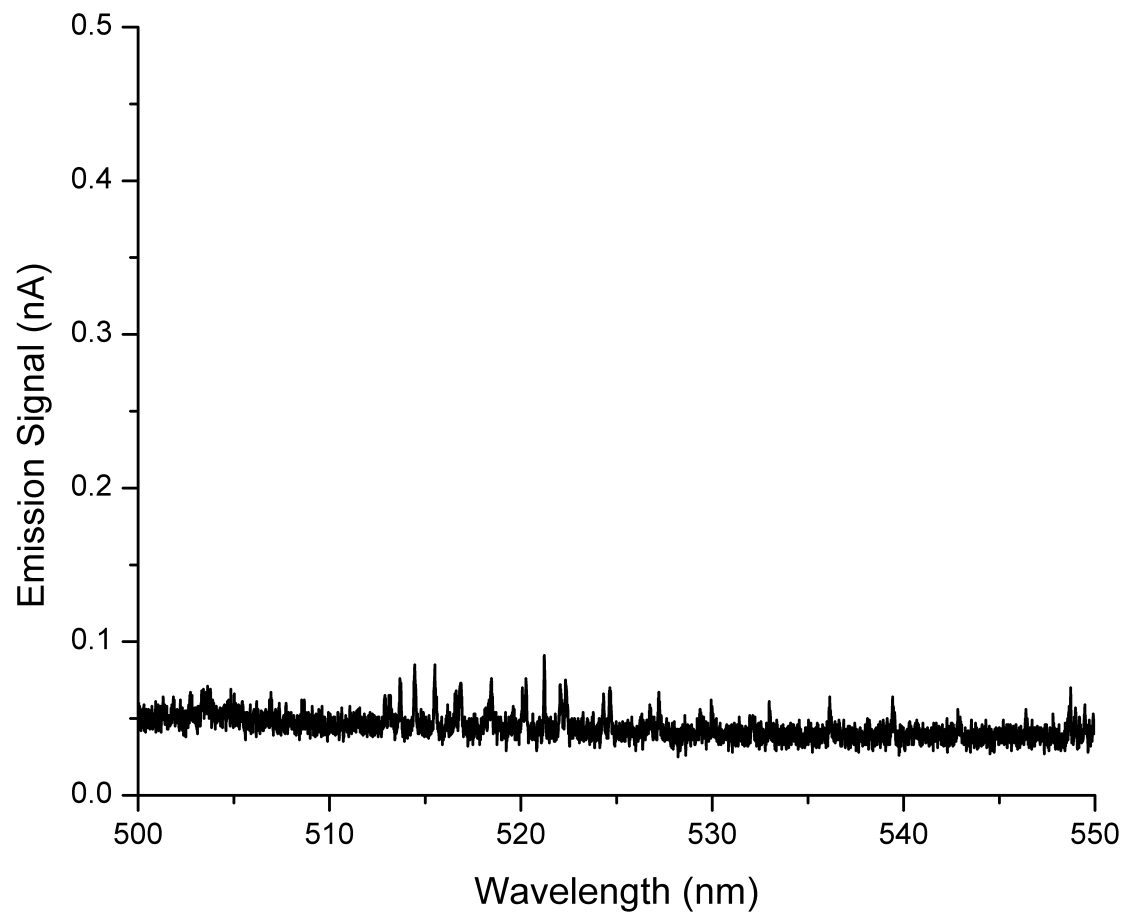


(j)

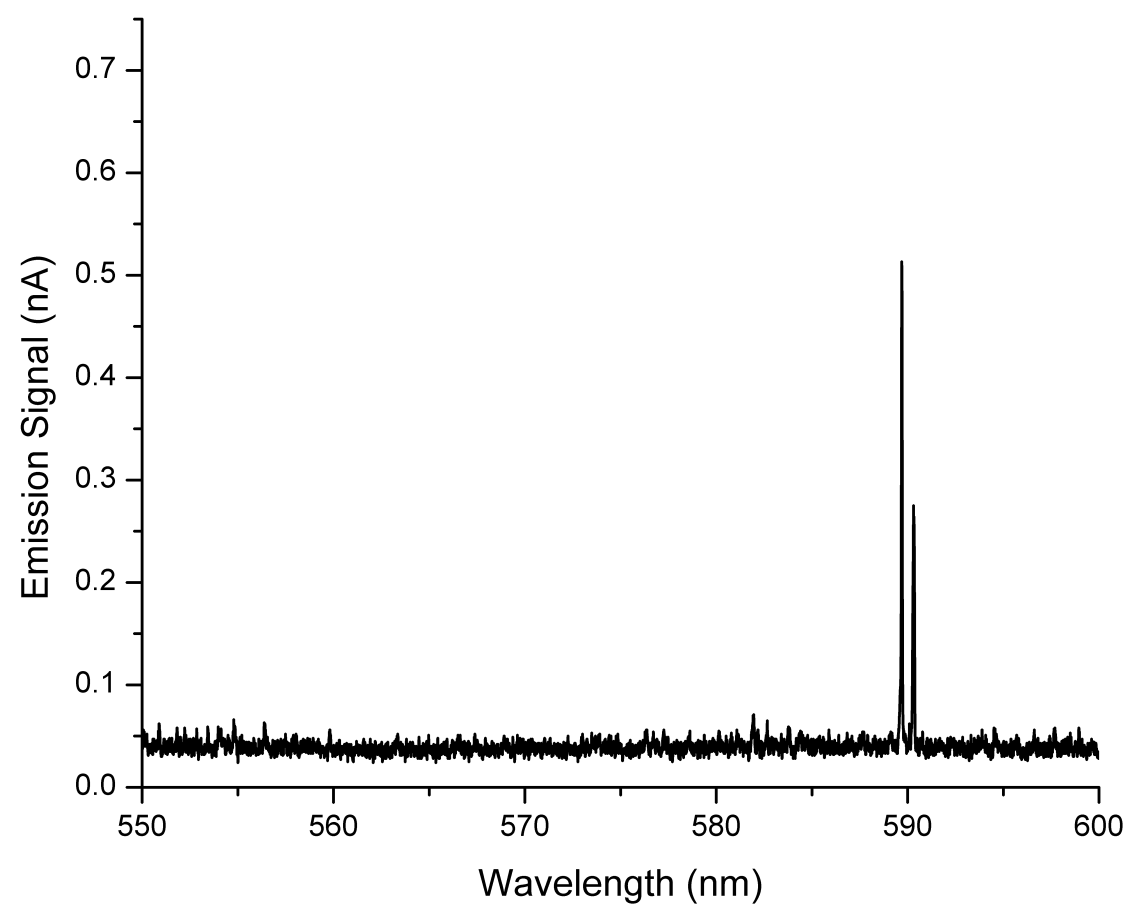

(k)

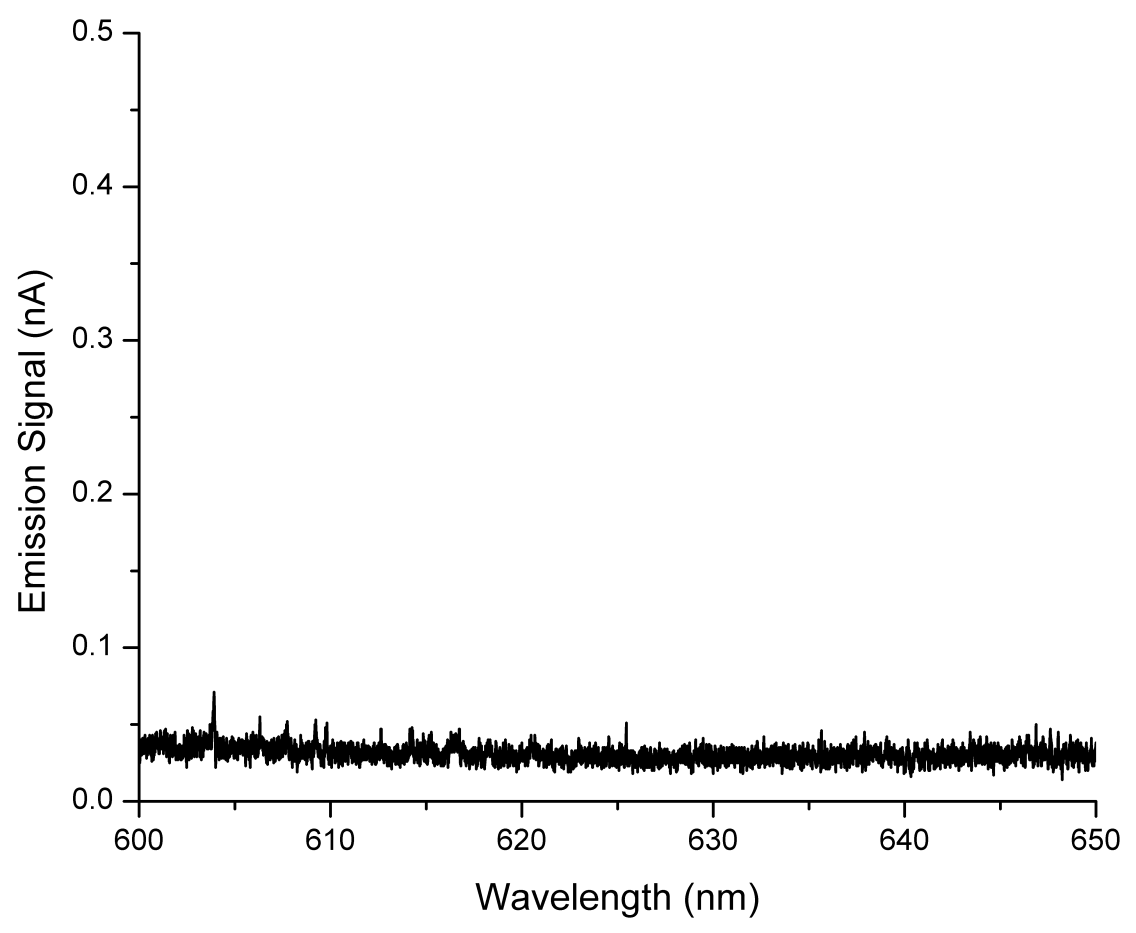


(I)

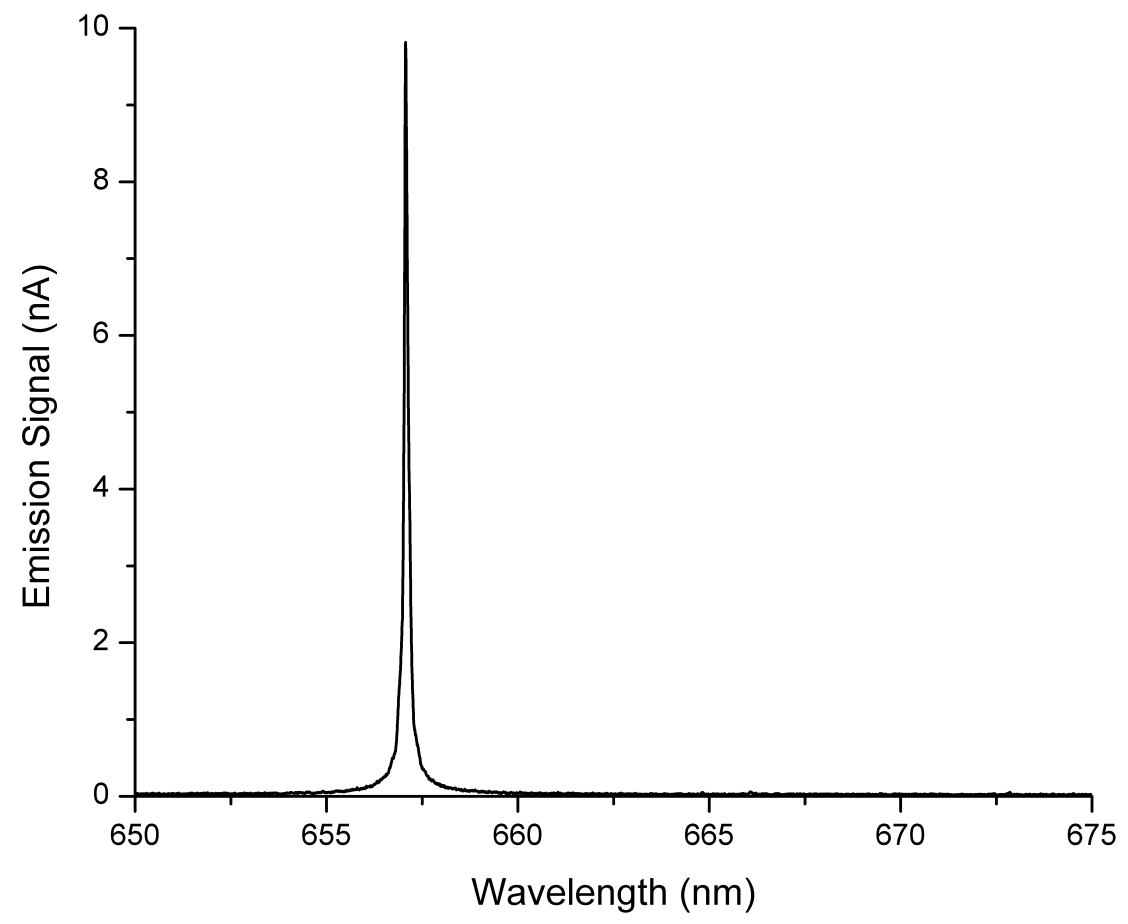

(m)

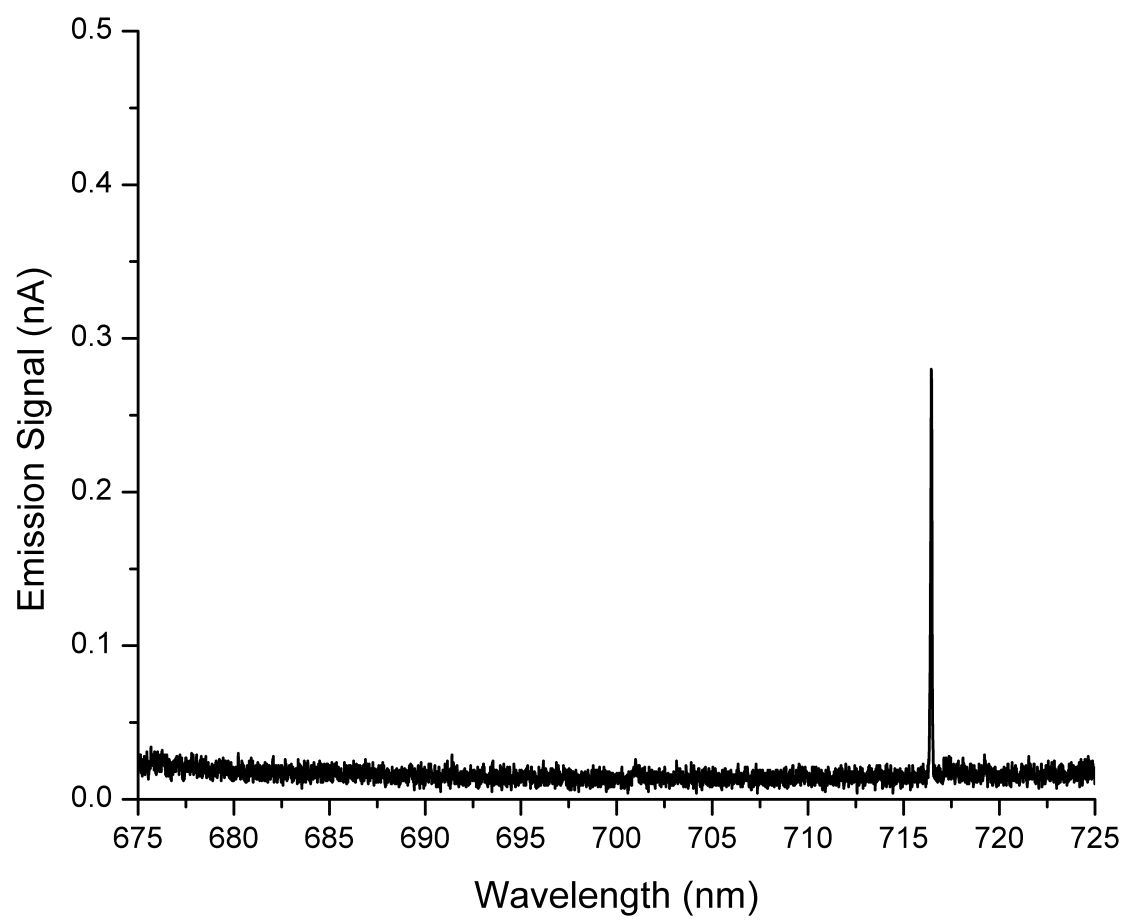


(n)

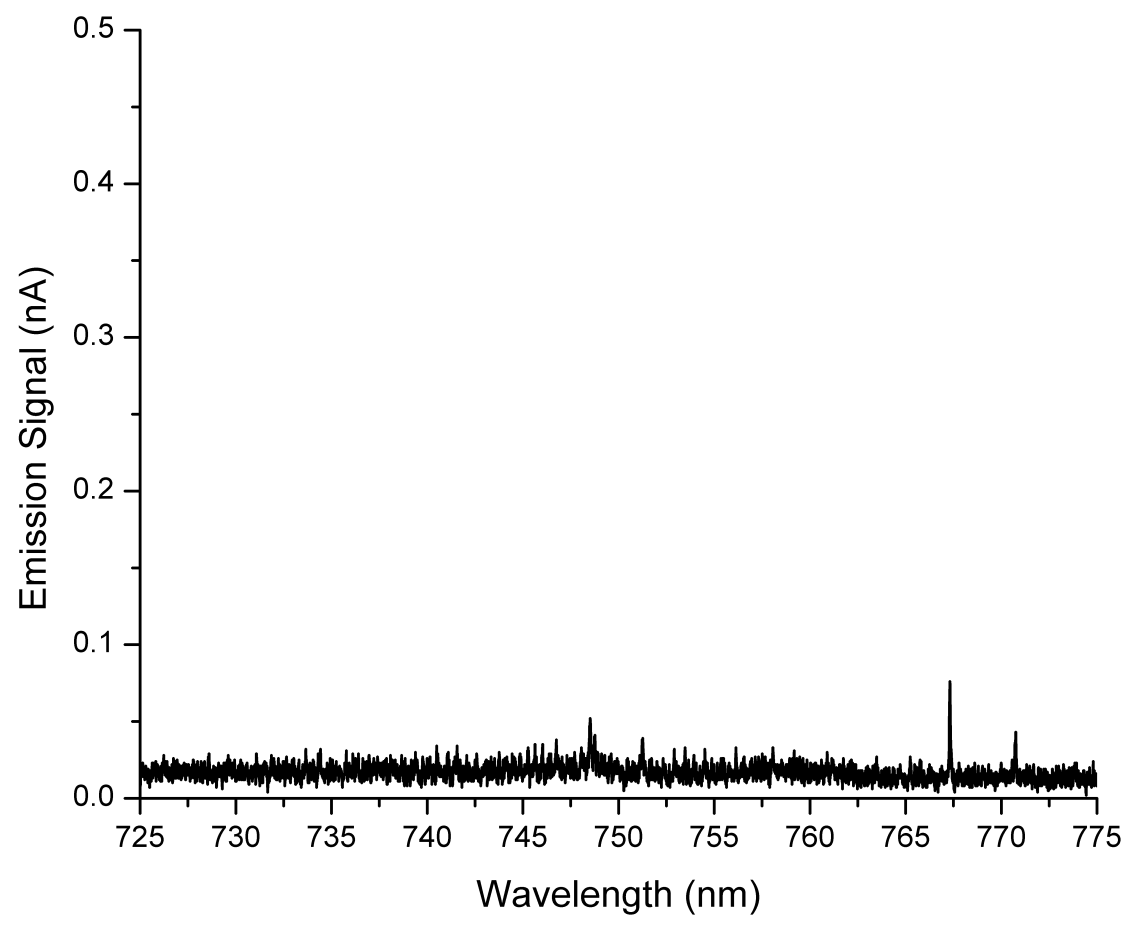

(o)

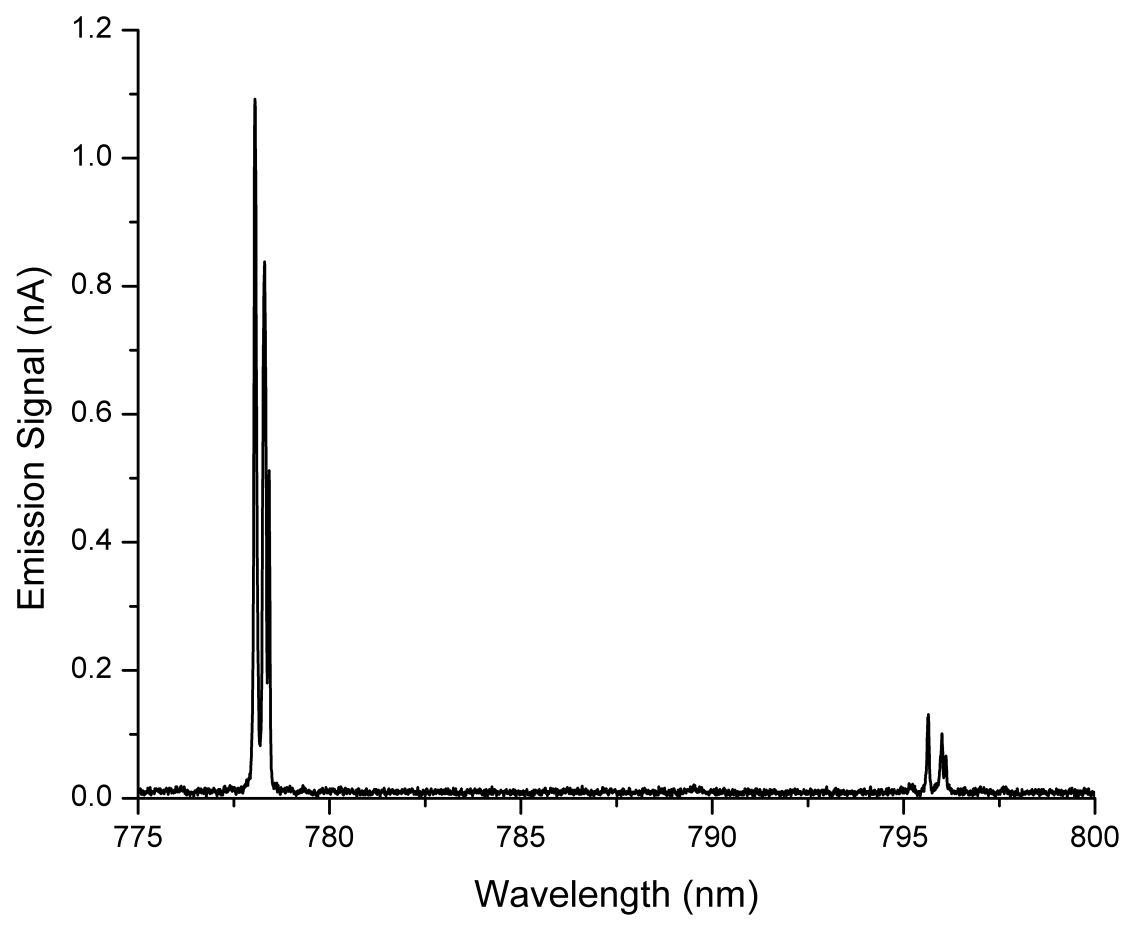

